\title{
Long Term Ocular Effects of Mustard Gas Poisoning: A Cross-Sectional Study in Iraqi Kurdish Civilians
}

\author{
Mostafa Naderi ${ }^{1}$, Mostafa Ghanei ${ }^{1}$, Khosro Jadidi ${ }^{1}$, Mohammad Gholami-Fesharaki ${ }^{2}$ and Zohreh Poursaleh ${ }^{1^{*}}$ \\ ${ }^{1}$ Chemical Injuries Research Center, Baqiyatallah University of Medical Sciences, Iran \\ ${ }^{2}$ Department of Biostatistics, Faculty of Medical Sciences, Tarbiat Modares University, Iran
}

"Corresponding author: Zohreh Poursaleh, Chemical Injuries Research Center, Baqiyatallah University of Medical Sciences, Tehran, Iran, Tel: 09122594523; Fax: +9821 882484511; E-mail: z_poursaleh@yahoo.com

Rec date: Apr 10, 2014, Acc date: May 30, 2014, Pub date: June 04, 2014

Copyright: (c) 2014 Naderi M, et al. This is an open-access article distributed under the terms of the Creative Commons Attribution License, which permits unrestricted use, distribution, and reproduction in any medium, provided the original author and source are credited.

\begin{abstract}
Background: Iraqi forces utilized a range of chemical weapons including sulfur mustard (SM) and other unknown chemical warfare agents against Iraqi Kurdish civilians in the 1980s. Little data exist regarding the chronic and delayed destructive lesions in the ocular organ caused by this exposure. The aim of this study was to evaluate and validate the severity of eye injuries in Kurdish subjects with chronic and delayed-onset mustard gas lesions.

Methods: This cross-sectional study conducted by simple random sampling on 303 people who had history of exposure to chemical weapons in February 2009 in Sulaimany, Iraq. Medical history, symptoms, ocular conditions, clinical course, and treatment measures were reviewed. Statistical analysis was accomplished using SPSS/18, Chisquare test.

Results: The present samples comprised of $49.8 \%$ were male and $50.2 \%$ were female. The mean age of the patients was $43.7 \pm 13.1$. Ophthalmic symptoms including tearing $(96.7 \%)$, itching $(96.0 \%)$, red eye $(95.4 \%)$, blurred vision $(84.2 \%)$, and vision loss $(37.3 \%)$ were most common in subjects from Halabja, who also made up the majority of participants. Moderate to severe mustard gas keratitis was seen in $12.9 \%$ subjects $(n=39)$, and severe complications were most common in subjects from Dukan.
\end{abstract}

Conclusion: The investigation findings suggest that the need of Iraqi Kurdish chemical warfare victims with moderate to severe ophthalmologic complications for the provision of healthcare and follow-up is urgent. Further research also is necessary to measure the results of follow-up on Kurdish victims with mustard gas keratitis.

Keywords: Sulfur mustard; Chemical warfare agent; Ocular; Keratitis; Long term

\section{Introduction}

It is known that the population of the Kurdistan region in Northeastern Iraq, just like Iranian military and civilian victims, had been targeted by the Iraqi military with chemical weapons between 1983 and 1988. On March 17, 1988, Iraqi airplanes bombed the village of Halabja, Iraq, killing upwards of 5000 people. The majority of the chemical agent victims have suffered chronic illnesses for many years that are consistent with chemical exposure $[1,2]$. Although the exact identity about the weapons' chemical composition and casualtyproducing effects is known yet, but the chemical weapons allegedly used were nerve agents, cyanide, and mustard agents. Breathing impairment is an early effect of exposure to the vapours or aerosol of nerve agents. Nerve agents in the eye may cause miosis, conjunctival infection, pain in or around the eye, as well as dim or blurred vision (or both) [3]. Sulfur mustard is a potent alkylating agent that has a strong irritating effect on living tissue and induces long-lasting radiomimetic effects. The long term effects of exposure to sulfur mustard usually include ocular, dermal, and/or respiratory tissues. Additionally, carcinogenic and mutagenic effects also have been reported $[1,4]$. The eye is the organ most sensitive to mustard gas, and about $75-90 \%$ of all mustard gas victims present with ocular injuries, according to a survey of Kurdish SM-exposed individuals. There is relatively little evidence regarding the delayed ocular complications of chemical agents in the civilian population of Kurdistan of Iraq [5]. Notwithstanding, many such chemical warfare cases, however, have been reported in British, French, and German literature about World War I [2], knowledge of effective strategies to reduce acute ocular complications caused by chemical agents as well as access to health care in this population was limited [5]. Therefore, recognition of the late effects of SM on the cornea is important to facilitate the service connection of the disabled from the Iraq-Iran war. In dealing with the health needs of this group of people; we have aimed to evaluate Mustard Gas Keratitis (MGK) in Iraqi Kurdish individuals reporting exposure to chemical weapons.

\section{Material and Methods}

\section{Study population}

Approval to conduct the study was obtained from the Baqiyatallah University of Medical Science's ethics committee. The Participants were briefed about the aim of the study and signed a written informed consent.

In this study, people who living in Northeastern Iraq and had sustained exposure to chemical warfare agents during the 1983-1988 
attacks (with or without health problems) invited to participate in a medical assessment by simple random sampling. Data collection was carried out during one week in February 2009 in Sulaimany, Iraq. The volunteers were attended four Iraqi Kurdish regions. An assessment which included a structured interview reviewing ocular history such as tearing, itching, redeye, blurred vision, and vision loss was performed. Then, anterior examinations using a slit lamp biomicroscope (Nidek model, Gamagori, Japan) were performed, including:

- A complete examination of the lids and an evaluation of the meibomian gland based on the current concept of meibomian gland dysfunction or diseases (MGD) [6,7].

- An evaluation of the tear status by tear break-up time (TBUT) and tear meniscus layer tests.

- An examination of the bulbar conjunctiva and limbal tissue, cornea, and anterior segment of the eye.

An evaluation of the posterior segment was carried out using direct and indirect ophthalmoscopy. The history of any ocular surgery was documented. Finally, the severity of the disease was noted, according to a chart from the Foundation of Martyrs and Veterans Affairs (Iranian Ophthalmic Committee of Chemical Warfare Veterans) [8], as follows:

- None: Absence of symptoms and signs.

- Without clinical evidence (WCE): Presence of photophobia, foreign body sensation, burning, itching, lacrimation, redness, and dryness such that MGK is considered to be unlikely.

- Mild: The WCE symptoms plus conjunctival disturbances including micro-aneurysm, telangiectasia, tortuosity, segmentation (venous beading) and vascular dilatation, ischemia, dryness of the eye, and clearness of the cornea.

- Moderate: Presence of manifestations of the mild form plus corneal involvement (epithelial or subepithelial opacity, peripheral and corneal stromal opacity, and neovascularization) and limbal ischemia.

- Severe: Presence of manifestations of the moderate form plus severe corneal involvement (melting, thinning, hyaline-like substance deposition, or diffuse corneal opacity) and any related operation such as amniotic membrane transplantation, lamellar keratoplasty, penetrating keratoplasty (PK), and stem cell graft.

In this study, a group is considered as Rule out MGK. They were suspected cases of sulfur mustard exposure, because they had experienced only the WCE symptoms and low limbic vascular changes similar to allergic conjunctivitis. These people should be followed up for manifestations of corneal involvement and limbic ischemia in the next years. Demographic data were assembled according to age, sex, and regional distribution of chemical agent exposure for the victims. Furthermore, data were gathered with regard to the severity of ocular injuries, especially cornea lesions such as MGK.

\section{Statistical analysis}

Data were analyzed with SPSS18. Continuous variables are presented as the mean $\pm \mathrm{SD}$, whereas categorical data are presented as frequency distribution and percentages. Qualitative data were analyzed by using chi square test. In this study, the probability value of 0.05 or less $(\mathrm{P} \leq 0.05)$ was set to know the significance level.

\section{Results}

Three hundred ten subjects (aged $43.7 \pm 13.1$ years) participated in the evaluation. Seven patients were excluded from analysis, one with rheumatoid arthritis, one with tuberculosis, one with scleroderma, and four with occupational exposure to dust. Therefore, the data in this paper correspond with 303 patients ranging in age from 21 to 80 years and the greater number of subjects came from Halabja. It is noteworthy to mention that the youngest participant in the study was 21 years of age, which means this victim would have been exposed as an infant. About $49.8 \%$ of participants had no signs of MGK, and $13.5 \%$ had suspicious signs of MGK (WCE); however, $12.9 \%$ of subjects suffered moderate to severe MGK. The severity of ocular disease and demographical variables are shown in Table 1.

\begin{tabular}{|c|c|c|c|}
\hline Variables & Level & $\mathbf{N}$ & $\%$ \\
\hline \multirow[t]{2}{*}{ Sex } & Female & 152 & $50.20 \%$ \\
\hline & Male & 151 & $49.80 \%$ \\
\hline \multirow[t]{4}{*}{ Age } & $<=30$ & 42 & $14.00 \%$ \\
\hline & $31-40$ & 72 & $24.10 \%$ \\
\hline & $41-50$ & 97 & $32.40 \%$ \\
\hline & $51+$ & 88 & $29.40 \%$ \\
\hline \multirow[t]{4}{*}{ Region } & Dukan & 17 & $5.60 \%$ \\
\hline & Hallabje & 179 & $59.10 \%$ \\
\hline & Jamjamal & 16 & $5.30 \%$ \\
\hline & Shaghlave & 91 & $30.00 \%$ \\
\hline \multirow[t]{2}{*}{ Tearing } & No & 10 & $3.30 \%$ \\
\hline & Yes & 293 & $96.70 \%$ \\
\hline \multirow[t]{2}{*}{ Itching } & No & 12 & $4.00 \%$ \\
\hline & Yes & 291 & $96.00 \%$ \\
\hline \multirow[t]{2}{*}{ Red Eye } & No & 14 & $4.60 \%$ \\
\hline & Yes & 289 & $95.40 \%$ \\
\hline \multirow[t]{2}{*}{ Blurred Vision } & No & 48 & $15.80 \%$ \\
\hline & Yes & 255 & $84.20 \%$ \\
\hline \multirow[t]{2}{*}{ Vision loss } & No & 190 & $62.70 \%$ \\
\hline & Yes & 113 & $37.30 \%$ \\
\hline \multirow{5}{*}{$\begin{array}{l}\text { Mustard Gass } \\
\text { Keratitis }\end{array}$} & No & 151 & $49.80 \%$ \\
\hline & Rule out MGK & 41 & $13.50 \%$ \\
\hline & Mild MGK & 72 & $23.80 \%$ \\
\hline & Moderate MGK & 20 & $6.60 \%$ \\
\hline & Severe MGK & 19 & $6.30 \%$ \\
\hline
\end{tabular}

Table 1: Distribution of demographical variable and severity of ocular injuries 
Citation: Naderi M, Ghanei M, Jadidi K, Gholami-Fesharaki M, Poursaleh Z (2014) Long Term Ocular Effects of Mustard Gas Poisoning: A

Page 3 of 5

Sex, age, and location of exposure were significantly associated with Mustard Gas Keratitis (Table 2). Severity of ocular disease and geographical distribution of chemical warfare survivor are shown in Table 2. Ocular symptoms such as tearing (94.7\%), itching (100\%), redeye $(100 \%)$, blurred vision $(94.7 \%)$, and vision loss $(47.4 \%)$ were present in the majority of participants. Tearing (100\%) was more common in mild MGK, while itching (100\%), red eye (100\%), blurred vision $(94.7 \%)$, and vision loss (47.4\%) were more common in severe MGK. The ocular symptoms appeared to be associated with case groupings; the associations between these symptoms and the severity of MGK were not statistically significant (Table 3 ).

\begin{tabular}{|c|c|c|c|c|c|c|c|c|c|c|c|c|}
\hline & & \multicolumn{10}{|c|}{ Mustard Gas Keratitis } & \multirow[b]{3}{*}{ P-value } \\
\hline & & \multicolumn{2}{|l|}{ No } & \multicolumn{2}{|c|}{ Rule out MGK } & \multicolumn{2}{|c|}{ Mild MGK } & \multicolumn{2}{|c|}{ Moderate MGK } & \multicolumn{2}{|c|}{ SevereMGK } & \\
\hline & & $\mathbf{N}$ & $\%$ & $\mathbf{N}$ & $\%$ & $\mathbf{N}$ & $\%$ & $\mathbf{N}$ & $\%$ & $\mathbf{N}$ & $\%$ & \\
\hline \multirow[t]{2}{*}{ Sex } & Female & 92 & $60.50 \%$ & 17 & $11.20 \%$ & 28 & $18.40 \%$ & 9 & $5.90 \%$ & 6 & $3.90 \%$ & \multirow[t]{2}{*}{0.005} \\
\hline & Male & 59 & $39.10 \%$ & 24 & $15.90 \%$ & 44 & $29.10 \%$ & 11 & $7.30 \%$ & 13 & $8.60 \%$ & \\
\hline \multirow[t]{4}{*}{ Age } & $<=30$ & 12 & $28.60 \%$ & 8 & $19.00 \%$ & 15 & $35.70 \%$ & 4 & $9.50 \%$ & 3 & $7.10 \%$ & \multirow[t]{4}{*}{$<0.0001$} \\
\hline & $31-40$ & 25 & $34.70 \%$ & 11 & $15.30 \%$ & 24 & $33.30 \%$ & 5 & $6.90 \%$ & 7 & $9.70 \%$ & \\
\hline & $41-50$ & 46 & $47.40 \%$ & 15 & $15.50 \%$ & 23 & $23.70 \%$ & 7 & $7.20 \%$ & 6 & $6.20 \%$ & \\
\hline & $51+$ & 66 & $75.00 \%$ & 6 & $6.80 \%$ & 9 & $10.20 \%$ & 4 & $4.50 \%$ & 3 & $3.40 \%$ & \\
\hline \multirow[t]{5}{*}{ Region } & Dukan & 5 & $29.40 \%$ & 2 & $11.80 \%$ & 4 & $23.50 \%$ & 2 & $11.80 \%$ & 4 & $23.50 \%$ & \multirow[t]{4}{*}{0.001} \\
\hline & Hallabje & 109 & $60.90 \%$ & 23 & $12.80 \%$ & 33 & $18.40 \%$ & 9 & $5.00 \%$ & 5 & $2.80 \%$ & \\
\hline & Jamjamal & 5 & $31.30 \%$ & 2 & $12.50 \%$ & 7 & $43.80 \%$ & 1 & $6.30 \%$ & 1 & $6.30 \%$ & \\
\hline & Shaghlave & 32 & $35.20 \%$ & 14 & $15.40 \%$ & 28 & $30.80 \%$ & 8 & $8.80 \%$ & 9 & $9.90 \%$ & \\
\hline & \multicolumn{10}{|c|}{${ }^{*} \mathrm{P}$ value calculated Base on Chi Square test } & & \\
\hline
\end{tabular}

Table 2: The variables relationship with ocular injuries

\begin{tabular}{|c|c|c|c|c|c|c|c|c|c|c|c|c|}
\hline & & \multicolumn{10}{|c|}{ Mustard Gass Keratitis } & \multirow[b]{3}{*}{$P$ value } \\
\hline & & \multicolumn{2}{|l|}{ No } & \multicolumn{2}{|c|}{ Rule out MGK } & \multicolumn{2}{|c|}{ Mild MGK } & \multicolumn{2}{|c|}{ Moderate MGK } & \multicolumn{2}{|c|}{ Severe MGK } & \\
\hline & & $\mathbf{N}$ & $\%$ & $\mathbf{N}$ & $\%$ & $\mathbf{N}$ & $\%$ & $\mathbf{N}$ & $\%$ & $\mathbf{N}$ & $\%$ & \\
\hline \multirow{2}{*}{ Tearing } & No & 7 & $4.6 \%$ & 1 & $2.4 \%$ & 0 & $0.0 \%$ & 1 & $5.0 \%$ & 1 & $5.3 \%$ & \multirow{2}{*}{0.433} \\
\hline & Yes & 144 & $95.4 \%$ & 40 & $97.6 \%$ & 72 & $100.0 \%$ & 19 & $95.0 \%$ & 18 & $94.7 \%$ & \\
\hline \multirow{2}{*}{ Itching } & No & 8 & $5.3 \%$ & 2 & $4.9 \%$ & 1 & $1.4 \%$ & 1 & $5.0 \%$ & 0 & $0.0 \%$ & \multirow{2}{*}{0.576} \\
\hline & Yes & 143 & $94.7 \%$ & 39 & $95.1 \%$ & 71 & $98.6 \%$ & 19 & $95.0 \%$ & 19 & $100.0 \%$ & \\
\hline \multirow{2}{*}{ Red Eye } & No & 9 & $6.0 \%$ & 2 & $4.9 \%$ & 1 & $1.4 \%$ & 2 & $10.0 \%$ & 0 & $0.0 \%$ & \multirow{2}{*}{0.335} \\
\hline & Yes & 142 & $94.0 \%$ & 39 & $95.1 \%$ & 71 & $98.6 \%$ & 18 & $90.0 \%$ & 19 & $100.0 \%$ & \\
\hline \multirow{2}{*}{ Blurred Vision } & No & 28 & $18.5 \%$ & 7 & $17.1 \%$ & 9 & $12.5 \%$ & 3 & $15.0 \%$ & 1 & $5.3 \%$ & \multirow{2}{*}{0.544} \\
\hline & Yes & 123 & $81.5 \%$ & 34 & $82.9 \%$ & 63 & $87.5 \%$ & 17 & $85.0 \%$ & 18 & $94.7 \%$ & \\
\hline \multirow{2}{*}{ Vision loss } & No & 96 & $63.6 \%$ & 26 & $63.4 \%$ & 45 & $62.5 \%$ & 13 & $65.0 \%$ & 10 & $52.6 \%$ & \multirow{2}{*}{0.920} \\
\hline & Yes & 55 & $36.4 \%$ & 15 & $36.6 \%$ & 27 & $37.5 \%$ & 7 & $35.0 \%$ & 9 & $47.4 \%$ & \\
\hline & \multicolumn{10}{|c|}{${ }^{*} \mathrm{P}$ value calculated Base on $\mathrm{Ch}$} & & \\
\hline
\end{tabular}

Table 3: The variables relationship with ocular injuries 


\section{Discussion}

In this investigation, we present the results of the first survey to study the ocular effects of chemical weapons use against the Kurdish people in Iraq that occurred at the end of the Iran-Iraq war in the 1980s. Those participants replied to a common invitation to attend a medical assessment. Most common problems in all injured Iranian survivors exposed to SMin the Iran-Iraq war have been reported in previous studies $[\mathbf{1 , 4}$. Similar to those symptoms we observed, Ghanei et al. reported a high incidence of respiratory symptoms in chemical weapon-exposed populations in Iraqi Kurdistan [9]. The use of blistering agents by the Iraqi army still is not known, but a history of blistering at the time of exposure was related, followed by delayed destructive lesions in the ocular surface and cornea, which led to progressive visual deterioration and ocular irritation. That is to say that despite being several kilometers away from the scene of the explosion of SM bombs, the presenting subjects showed different residual symptoms of poisonous gas effects [2]. The presence of ocular symptoms and signs in our survey would suggest that these individuals had in fact been exposed to SM. The reaction of SM in subjects is dependent on the size of the dose and the anatomical distribution. The effects of vapour and liquid are different only when the real amount of SM which infuses into the tissue is different. Therefore, it is very difficult to assess the value of treatment in Iraqi Kurdish participants since the dose of SM received can never be known, and no two cases will be comparable; i.e. two eyes of the same patient may be comparable though by no means always, even when the lesions are caused by vapour [3]. An asymptomatic period for the eyes is followed by redness and irritation which can progress to corneal damage with photophobia, blepharospasm, excessive lacrimation, and blindness $[8,10,11]$. At first, SM causes vasodilation and increased vascular permeability in the conjunctiva, which lead to progressive edema and secretion of mucus. Pyknosis of epithelial cells leads to desquamation of the epithelium. In the later stages, inflammatory infiltration of connective tissue and exudation are present. The injury due to persistent morphologic abnormalities is limited to the anterior segment of the eye $[12,13]$. In our study, the symptomatology of ocular disease was different compared with Iranian victims exposed to chemical agents during the Iran-Iraq war. In an Iranian group study, patients with confirmed SM poisoning 16 to 20 years after exposure displayed common symptoms such as itching (42.5\%), burning sensations (37.5\%), photophobia (30.0\%), and tearing $(27.5 \%)[14,15]$. Surprisingly, in the present study, tearing was more common $(96.7 \%)$, while redeye $(95.4 \%)$, itching $(96.0 \%)$, blurred vision $(84.2 \%)$, and vision loss (37.3\%) were more common in severe MGK. Almost half (50.2\%) of subjects showed symptoms and/or signs of ocular complications that indicated MGK; $12.9 \%$ of participants with abnormal ocular findings were in the moderate to severe MGK categories. While similar this research, in a population of 34,000 Iranians with histories of mustard agent exposure, however, $60.7 \%$ had normal eyes, $35 \%$ had mild ocular problems, $3.6 \%$ had moderate ocular problems, and $0.7 \%$ had severe ocular lesions, respectively [1]. Also, in Iranian victims in the city of Marivan, Iran, $74.0 \%$ had no ocular problems, while $25.8 \%, 0.2 \%$, and $0 \%$ had mild, moderate, and severe ocular problems, respectively [14]. In the mild category, the most frequent findings were conjunctival disturbances such as recurrent chronic inflammation, vascular abnormalities, ischemia; pigment changes, and decreased tear secretion, whereas in the mild to moderate category, corneal lesions were added to the other problems. Thus, ocular injury is one of the distressing conditions resulting from mustard agent attacks. Therefore, the most interesting finding was that when an ocular damaging process happened, it developed more quickly in the Iraqi Kurdish population than in Iranian subjects. A possible explanation for this might be that Iranian physicians were familiar with SM effects, in addition to the early application of countermeasures such as removing contaminated clothing, washing exposed tissues, and applying neutralizing agents could have been expected to reduce complications and encourage a rapid recovery in Iranian subjects $[9,15]$. However, there were other factors that could modulate exposure severity, such as the increased dose of chemical agents, different environmental conditions and distance from the attack location in the Iraqi Kurdish population.

\section{Study Limitations}

There were many limitations of this survey, including the condition that subjects were self-selected rather than randomly identified. There was no data registry system or hospitalization record to establish the either the agent or duration of exposure. It is therefore possible that those presenting to the clinical locations of this study did not comprise all civilians in the general population with late ocular complications caused by exposure to chemical warfare agents. Also, recall bias was possible, as the events occurred more than 20 years ago. Moreover, there were no data on the prevalence of abnormalities in a matched, healthy, control Kurdish population for comparison.

\section{Conclusions}

The results clearly showed that ocular complications in Iraqi Kurdish victims exposed to chemical weapons persist without special treatment or suitable medical care after more than 20 years. Thus, there are still people in the contaminated area who suffer ocular symptoms and may be at risk for late complications; there is a sustained need for early recognition and monitoring for late-term developments. Immediate treatment of moderate to severe cases of delayed mustard gas keratopathy can mitigate ocular irritation and improve vision.

\section{Acknowledgements}

The authors would like to thank Dr. Yunes Panahi (Chemical Injuries Research Center, Baqiyatallah University of Medical Sciences) for their support and contribution to this study.

\section{References}

1. Khateri S, Ghanei M, Keshavarz S, Soroush M, Haines D (2003) Incidence of lung, eye, and skin lesions as late complications in 34,000 Iranians with wartime exposure to mustard agent. J Occup Environ Med 45: 1136-1143.

2. Mohamed-Ali H (1992) [Late lesions due to poison gas in survivors of the Iraqi poison warfare against the Kurdish people]. Wien Med Wochenschr 142: 8-15.

3. Kasthuri AS, Pradhan AB, Dham SK, Bhalla IP, Paul JS (1990) Nuclear, biological and chemical warfare. Part III: Medical aspectsof chemical warfare. J Assoc Physicians India 38: 292-294.

4. Rowell M, Kehe K, Balszuweit F, Thiermann H (2009) The chronic effects of sulfur mustard exposure. Toxicology 263: 9-11.

5. Dworkin J, Prescott M, Jamal R, Hardawan SA, Abdullah A, et al. (2008) The long-term psychosocial impact of a surprise chemical weapons attack on civilians in Halabja, Iraqi Kurdistan. J Nerv Ment Dis 196: 772-775.

6. Lin PY, Cheng CY, Hsu WM, Tsai SY, Lin MW, et al. (2005) Association between symptoms and signs of dry eye among an elderly Chinese 
Citation: Naderi M, Ghanei M, Jadidi K, Gholami-Fesharaki M, Poursaleh Z (2014) Long Term Ocular Effects of Mustard Gas Poisoning: A Cross-Sectional Study in Iraqi Kurdish Civilians. J Allergy Ther 5: 177. doi:10.4172/2155-6121.1000177

Page 5 of 5

population in Taiwan: the Shihpai Eye Study. Invest Ophthalmol Vis Sci 46: 1593-1598.

7. Yamada M, Mochizuki H, Kawai M, Tsubota K, Bryce TJ (2005) Decreased tear lipocalin concentration in patients with meibomian gland dysfunction. Br J Ophthalmol 89: 803-805.

8. Balali-Mood M, Hefazi M (2006) Comparison of early and late toxic effects of sulfur mustard in Iranian veterans. Basic Clin Pharmacol Toxicol 99: 273-282.

9. Ghanei M, Naderi M, Kosar AM, Harandi AA, Hopkinson NS, et al. (2010) Long-term pulmonary complications of chemical warfare agent exposure in Iraqi Kurdish civilians. Inhal Toxicol 22: 719-724.

10. Kehe K, Szinicz L (2005) Medical aspects of sulphur mustard poisoning. Toxicology 214: 198-209.

11. MAUMENEE AE, SCHOLZ RO (1948) The histopathology of the ocular lesions produced by the sulfur and nitrogen mustard. Bull Johns Hopkins Hosp 82: 121-147.
12. McNutt P, Hamilton T, Nelson M, Adkins A, Swartz A, et al. (2012) Pathogenesis of acute and delayed corneal lesions after ocular exposure to sulfur mustard vapor. Cornea 31:280-290.

13. Lagali N, Fagerholm P (2009) Delayed mustard gas keratitis: clinical course and in vivo confocal microscopy findings. Cornea 28: 458-462.

14. Etezad-Razavi M, Mahmoudi M, Hefazi M, Balali-Mood M (2006) Delayed ocular complications of mustard gas poisoning and the relationship with respiratory and cutaneous complications. Clin Experiment Ophthalmol 34: 342-346.

15. Ghasemi H, Ghazanfari T, Ghassemi-Broumand M, Javadi MA, Babaei $\mathrm{M}$, et al. (2009) Long-term ocular consequences of sulfur mustard in seriously eye-injured war veterans. Cutan Ocul Toxicol 28: 71-77. 